\title{
Sustained Deficit Irrigation and Mulching on Growth of Sourani Olive Trees in Kuwait
}

\author{
A. Al-Shatti, Habibah S. Al-Menaie* \\ Kuwait Institute for Scientific Research, Safat, Kuwait \\ Email: ${ }^{*}$ hmanaie@kisr.edu.kw
}

Received 7 May 2015; accepted 22 August 2015; published 25 August 2015

\begin{abstract}
Olea europaea, a native plant of the Mediterranean region, is of great interest to agronomists worldwide, owing to its health beneficial properties and tolerance to harsh environmental conditions, along with its economic importance. The productivity and production efficiency of olive is linearly related to both the level of transpiration and the amount of water supplied. Under conditions of limited supply of good quality water for irrigation in Kuwait, deficit irrigation applied at selected phenological stages can maximize economic gains and minimize environmental damage. Moreover, mulching contributes to a significant reduction in water requirements via reducing soil water losses and increasing soil water retention. In this study, the effects of different irrigation levels, a restitution of $50 \%, 75 \%$ or $100 \%$ of the estimated evapotranspiration rate $\left(\mathrm{ET}_{\mathrm{c}}\right)$, and the application of mulching on plant growth under the Kuwait environmental conditions were determined to evaluate the possibilities of reducing the amounts of water supplied with irrigation. Various parameters determining the vegetative growth of the trees such as average height, stem girth and number of branches were recorded at three months intervals. Both the irrigation level and mulching were shown to possess a significant impact on growth of Sourani olive cultivar under the Kuwait environmental conditions. Statistical analysis revealed no significant difference in the height of the trees under all the three irrigation treatments with mulch and trees under $100 \% \mathrm{ET}_{c}$ devoid of mulch. In contrast, a significant difference was exhibited by trees under $100 \% \mathrm{ET}_{\mathrm{c}}$ with mulch and $50 \% \mathrm{ET}_{\mathrm{c}}$ without mulch. Within each irrigation treatment, trees with mulch presented higher values for plant height, stem girth and number of shoots. Thus deficit irrigation of $50 \% \mathrm{ET}_{\mathrm{c}}$ along with organic mulch was shown to enhance vegetative growth close to its maximum potential by conserving the scarce water resources.
\end{abstract}

\section{Keywords}

Mulch, Olive, Deficit Irrigation

\section{Introduction}

Olive is considered as one of the most important crops in the world, with a total cultivated area over 9.6 million ha in 2011 and an average yield of 2.1 t/ha (FAO, 2013) [1]. Olive trees were first introduced and evaluated by

\footnotetext{
${ }^{*}$ Corresponding author.
} 
the Kuwait Institute for Scientific Research (KISR) in 1985 (Taha and Bhat, 2002) [2]. Later in 1990, approximately 300 seedlings were planted in Green Island in the waterfront project. While all trees flourished and grew very well, only some produced fruits. Since then, public interest in this plant has increased considerably. Recognizing the enormous potential of this tree, KISR developed and implemented a comprehensive research program for developing sustainable olive growing in Kuwait.

According to Ramos and Santos (2009) [3], the irrigation of olive trees increases the fruit bearing capacity, allowing the expansion of cultivation into regions that are too dry for rain fed production. Razouk et al. (2013) [4] reported that the irrigation during the early phase of fruit growth in an irrigation study in the climatic conditions of Morocco conducted over two years improved vegetative growth and increased yield without significant loss of olive oil content with a good efficiency of water use.

The scarcity and high cost of water in Kuwait demand a careful determination of the optimal economical impact of any amount of water applied. Although the yield increase in several perennial crops is linearly related to the level of transpiration, the effect of added irrigation water, in many cases, is not. Hence, the effectiveness and economic value of each cubic meter of water used, versus full irrigation systems, must be evaluated. Goldhamer (1999) [5] reported that reducing the optimal irrigation requirement of olive trees in summer by $25 \%$ did not reduce the final fruit yield under California's environmental conditions. Martinellia et al. (2012) [6] mentioned that primary metabolites, such as carbohydrates, amino acids, organic acids, and secondary metabolites, such as squalene and simple phenols, increased after performing irrigation, while polyphenols level increased in the rain fed fruit which at ripening showed an increase in anthocyanin concentration.

According to Chehab et al. (2009) [7], reduction of irrigation water (50\% $\mathrm{ET}_{\mathrm{c}}$ ) induced higher accumulation of glucose in the leaves and the wood of Meski, and an accumulation of mannitol and glucose in the wood, and mannitol in the leaves of Picholine olives. Therefore, the present trend of olive tree irrigation is to develop either sustained deficit irrigation (SDI) or regulated deficit irrigation (RDI) strategies, according to which water is applied at a rate that is less than the needs of evapotranspiration, with only very small reductions in yield (Goldhamer, 1999) [5]. Ramos and Santos (2010) [8] reported that olive oil production of sustained deficit irrigation (SDI) treatment with $60 \%$ of $\mathrm{ET}_{\mathrm{c}}$ water applied with irrigation was $32.5 \%$ and $40.1 \%$ higher in 2006 and 2007, respectively than the fully irrigated treatment, despite receiving $49 \%$ less irrigation water. Such strategy could allow for an efficient use of water in the region, of very limited available resources, and for modest, but important oil yield increase.

The SDI applies a fixed fraction of the ET rate throughout the irrigation season, while the RDI imposes a period of water stress that is controlled in terms of its intensity. The main advantages of SDI and RDI are the savings of water, maintenance of high yields, and positive effects on olive oil quality. Under conditions of scarce water supply and drought, the application of SDI and RDI irrigation regimes at selected phenological phases can lead to greater economic gains rather than simply maximizing yields per unit of water as shown by Tognetti et al. (2006) [9]. Crop-water balance models can assist in defining optimum canopy size for productivity and survival.

Another factor that can affect the amount of water to supply with irrigation is mulching. Indeed, especially in arid environments, the application of this technique can contribute to a significant reduction in water requirements, as a result of both a decrease of soil water losses and an increase of soil water retention.

In order to evaluate the possibilities of reducing the amounts of water supplied with irrigation, it was carried out the present investigation to determine the effects of different irrigation levels, namely, a restitution of $50 \%$, $75 \%$ or $100 \%$ of estimated $\mathrm{ET}_{c}$, and the application of mulching on plant growth under the Kuwait environmental conditions.

\section{Materials and Methods}

Experimental design: The experiment was conducted at the Agricultural Research Station (ARS) situated in Sulaibya, Kuwait in October 2012. Ninety one-year old acclimatized plants of the Sourani variety were planted in 50-cm diameter holes dug at $6 \times 6 \mathrm{~m}$ spacing. After planting, the plants were irrigated with available freshwater and fertilized by supplying $150 \mathrm{~N}+80 \mathrm{P}_{2} \mathrm{O}+100 \mathrm{~K}_{2} \mathrm{O}$ gm/tree. A complete randomized block design with six factorial combinations which constituted of three irrigation levels (T1 $=50 \%$, T2 $=75 \%$, and $\mathrm{T} 3=100 \%$ of estimated $\mathrm{ET}_{\mathrm{c}}$ ) (Table 1) and organic mulch treatment (wood cuttings) was tested. Water meter was used to measure the required volume of water supplied through drip irrigation system.

The actual crop evapotranspiration $\left(\mathrm{ET}_{\mathrm{c}}\right)$ of young olive plants was determined using capacitance probe, 
Table 1. Total quantity of irrigation applied to olive trees (liters/tree/month) submitted to different irrigation regimes (50\%, $75 \%$ or $100 \%$ of $\mathrm{ET}_{\mathrm{c}}$ ).

\begin{tabular}{cccc}
\hline Months & $100 \% \mathrm{ET}_{\mathrm{c}}$ & $75 \% \mathrm{ET}_{\mathrm{c}}$ & $50 \% \mathrm{ET}_{\mathrm{c}}$ \\
\hline 3 & 126.6 & 94.95 & 63.3 \\
6 & 64.8 & 48.6 & 32.4 \\
9 & 250.5 & 187.875 & 125.25 \\
12 & 114.6 & 85.95 & 57.3 \\
15 & 126.6 & 94.95 & 63.3 \\
18 & 64.8 & 48.6 & 32.4 \\
\hline
\end{tabular}

which measured apparent dielectric constant of the soil surrounding the sensor. Reference evapotranspiration $\left(\mathrm{ET}_{0}\right)$ was calculated using the FAO-Pennan-Monteith equation and procedure described by Allen et al. (1998) [10]. Crop coefficient (Kc) was estimated on a daily basis and averaged monthly using the equation as follows:

$$
\mathrm{Kc}=\mathrm{ET}_{\mathrm{c}} / \mathrm{ET}_{0}
$$

Several vegetative growth parameters of the trees such as average height, stem girth and number of shoots per plant were studied.

\section{Results}

Plant height: The pooled analysis of variance on the six factorial combinations obtained with three irrigation levels $\left(100 \% \mathrm{ET}_{\mathrm{c}}, 75 \% \mathrm{ET}_{\mathrm{c}}\right.$, and $50 \% \mathrm{ET}_{\mathrm{c}}$ ) and two organic mulch treatments (with or without mulch) after 18 months post planting indicated no significant difference in the height of the trees under all the three irrigation treatments with mulch and trees under $100 \% \mathrm{ET}_{\mathrm{c}}$ devoid of mulch. In contrast, a significant difference was observed between these trees and trees under $75 \%$ ETc and $50 \% \mathrm{ET}_{\mathrm{c}}$ with no mulch (Table 2). It was interesting to note that the lower growth of trees grown under $50 \% \mathrm{ET}_{\mathrm{c}}$ without mulch was detectable at 3 months post planting. Moreover, within each irrigation treatment, higher values were obtained with application of mulch. The results obtained were in agreement with the previous studies in which a reduced elongation of shoot was observed in young olives under deficit irrigation of $50 \%$ and $75 \% \mathrm{ET}_{\mathrm{c}}$ when compared to $100 \% \mathrm{ET}_{\mathrm{c}}$ (Correa-Tedesco et al., 2010; Pérez-López et al., 2007) [11] [12].

Stem girth: The statistical analysis of interactive effect of irrigation and mulch on stem girth of trees reported no significant difference between the treatments (Table 3). Similarly no significant effect was imposed by irrigation on trunk diameter of young olives in the initial growing season in a previous study (Gómez-del-Campo, 2013) [13]. In contrast, Tedesco et al. (2010) reported an increase in the trunk cross sectional area with the amount of irrigation applied.

Number of shoots: The number of shoots per plant increased during the experiment in all the trees. The statistical analysis after 18 months post planting reported no significant variation in the number of shoots produced by trees under $100 \% \mathrm{ET}_{\mathrm{c}}, 75 \% \mathrm{ET}_{\mathrm{c}}, 50 \% \mathrm{ET}_{\mathrm{c}}$ with mulch and $100 \% \mathrm{ET}_{\mathrm{c}}$ and $75 \% \mathrm{ET}_{\mathrm{c}}$ without mulch (Table 4). However, the number of shoots produced by plants under these treatments varied significantly from those trees under $50 \% \mathrm{ET}_{\mathrm{c}}$ without mulch. This reduction in the shoot growth was in agreement with the results obtained from previous studies on the effect of water status on shoot growth under deficit irrigation conditions (Tognetti et al.; 2006Grattan et al., 2006) [9] [14].

Water-use efficiency: The amounts of water supplied, calculated according to monthly estimations of crop evapotranspiration $\left(\mathrm{ET}_{\mathrm{c}}\right.$ ) and restitution of $50 \%, 75 \%$ and $100 \%$ of estimated $\mathrm{ET}_{\mathrm{c}}$ are reported in Table 1. The ratios between plant height or stem girth, or number of shoots at 18 months and the average amount of water supplied monthly to trees indicate a higher water-use efficiency if the water-use efficiency is considered, it appears that an efficient use of water and a relatively good growth could be obtained with $75 \% \mathrm{ET}_{\mathrm{C}}$ or, even better, with $50 \%$ of $\mathrm{ET}_{\mathrm{c}}+$ mulch.

\section{Conclusion}

The study highlighted the significant and positive effects of both irrigation level and mulching on plant growth. 
Table 2. The effect of interaction between irrigation and mulch on plant height (cm).

\begin{tabular}{|c|c|c|c|c|}
\hline \multirow{2}{*}{ Mulch } & \multicolumn{3}{|c|}{ Irrigation } & \multirow{2}{*}{ Mean } \\
\hline & $100 \% \mathrm{ET}_{\mathrm{c}}$ & $75 \% \mathrm{ET}_{\mathrm{c}}$ & $50 \% \mathrm{ET}_{\mathrm{c}}$ & \\
\hline Mulch & 55.20 & 48.57 & 46 & 49.92 \\
\hline Non mulch & 50.54 & 45.86 & 31.07 & 42.29 \\
\hline \multirow[t]{4}{*}{ Mean } & 52.87 & 47.21 & 38.53 & 46.10 \\
\hline & \multicolumn{2}{|c|}{ L.S.D0.05 for: Irrigation } & \multicolumn{2}{|c|}{0.91} \\
\hline & \multicolumn{2}{|c|}{ Mulch } & \multicolumn{2}{|c|}{11.76} \\
\hline & \multicolumn{2}{|c|}{ Irrigation * much } & \multicolumn{2}{|c|}{11.76} \\
\hline
\end{tabular}

Table 3. The effect of interaction between irrigation and mulch on stem girth.

\begin{tabular}{|c|c|c|c|c|}
\hline \multirow{2}{*}{ Mulch } & \multicolumn{3}{|c|}{ Irrigation } & \multirow{2}{*}{ Mear } \\
\hline & $100 \% \mathrm{ET}_{\mathrm{c}}$ & $75 \% \mathrm{ET}_{\mathrm{c}}$ & $50 \% \mathrm{ET}_{\mathrm{c}}$ & \\
\hline Mulch & 10.18 & 8.97 & 8.41 & 9.19 \\
\hline Non mulch & 8.79 & 8.83 & 7.12 & 8.25 \\
\hline \multirow[t]{4}{*}{ Mean } & 9.48 & 8.91 & 7.76 & 7.72 \\
\hline & \multicolumn{2}{|c|}{ L.S.D 0.05 for: Irrigation } & \multicolumn{2}{|c|}{0.91} \\
\hline & \multicolumn{2}{|c|}{ Mulch } & \multicolumn{2}{|c|}{11.76} \\
\hline & \multicolumn{2}{|c|}{ Irrigation * mulch } & \multicolumn{2}{|c|}{11.76} \\
\hline
\end{tabular}

Table 4. The effect of interaction between irrigation and mulch on number of shoots.

\begin{tabular}{|c|c|c|c|c|c|}
\hline \multirow{2}{*}{ Mulch } & \multicolumn{3}{|c|}{ Irrigation } & & \multirow{2}{*}{ Mean } \\
\hline & $100 \% \mathrm{ET}_{\mathrm{c}}$ & $75 \% \mathrm{ET}_{\mathrm{c}}$ & $50 \% \mathrm{ET}_{\mathrm{c}}$ & & \\
\hline Mulch & 24.97 & 23.40167 & 21.73333 & & 23.37 \\
\hline Non mulch & 20.57 & 20.00667 & 12.90167 & & 17.83 \\
\hline Mean & 22.77 & 21.70 & 17.32 & & 20.60 \\
\hline \multicolumn{3}{|c|}{ L.S.D 0.05 for: Irrigation } & \multicolumn{3}{|c|}{2.160} \\
\hline \multicolumn{3}{|c|}{ Mulch } & \multicolumn{3}{|c|}{11.76} \\
\hline \multicolumn{3}{|c|}{ Irrigation * mulch } & \multicolumn{3}{|c|}{11.70} \\
\hline
\end{tabular}

Analysis of various growth determining parameters under various treatments indicated that an irrigation level of $50 \% \mathrm{ET}_{\mathrm{c}}$ with organic mulching determined a growth which was always not statistically different from that promoted by $75 \% \mathrm{ET}_{\mathrm{C}}$. Thus sustained deficit irrigation (SDI) of $50 \% \mathrm{ET}_{\mathrm{c}}$ at this stage of growth of the trees could be an effective as well as economic approach towards saving scarce irrigation water resources without important reduction of tree growth by exploiting the good interaction between this level of irrigation and the application of mulch. As the drought tolerance and water requirements varies at different development phases of the trees, a continued investigation of growth performance of olive trees under various irrigation regime throughout its life cycle would be beneficial in optimizing the irrigation schedules applied for olive orchards under Kuwait's harsh environmental conditions.

\section{References}

[1] FAO (2013) Food and Agriculture Organization of the United Nations. FAO Statistics Division. http://faostat.fao.org

[2] Taha, F.K. and Bhat N.R. (2002) Selection of Ornamental and Landscape Plants for the Implementation of the National Greenery Plan of Kuwait. In: Al-Awadhi, N. and Taha, F.K., Eds., New Technologies for Soil Reclamation and Desert 
Greenery, Amherst Scientific Publishers, Amherst, 27-44.

[3] Ramos, A.F. and Santos F.L. (2009) Water Use, Transpiration, and Crop Coefficients for Olives (cv. Cordovil), Grown in Orchards in Southern Portugal. Biosystems Engineering, 102, 321-333. http://dx.doi.org/10.1016/j.biosystemseng.2008.12.006

[4] Razouk, R., Ibijbijen, J. and Kajji, A. (2013) Optimal Time of Supplemental Irrigation during Fruit Development of Rainfed Olive Tree (Olea europaea, cv. Picholine marocaine) in Morocco. American Journal of Experimental Agriculture, 4, 685-697. http://dx.doi.org/10.9734/ajea/2013/3348

[5] Goldhamer, D.A. (1999) Regulated Deficit Irrigation for California Canning Olives. Acta Horticulturae, 474, $369-372$. http://dx.doi.org/10.17660/actahortic.1999.474.76

[6] Martinellia, F., Basile, B., Morellid, G., d’Andria, R. and Tonuttia, P. (2012) Effects of Irrigation on Fruit Ripening Behavior and Metabolic Changes in Olive. Scientia Horticulturae, 144, 201-207. http://dx.doi.org/10.1016/j.scienta.2012.07.012

[7] Chehab, H., Mechri, B., Mariem, F.B., Hammami, M., Ben Elhadj, S. and Braham, M. (2009) Effect of Different Irrigation Regimes on Carbohydrate Partitioning in Leaves and Wood of Two Table Olive Cultivars (Olea europaea L. cv. Meski and Picholine). Agricultural Water Management, 96, 293-298. http://dx.doi.org/10.1016/j.agwat.2008.08.007

[8] Ramos, A.F. and Santos, F.L. (2010) Yield and Olive Oil Characteristics of a Low-Density Orchard (cv. Cordovil) Subjected to Different Irrigation Regimes. Agricultural Water Management, 97, 363-373. http://dx.doi.org/10.1016/j.agwat.2009.10.008

[9] Tognetti, R., d'Andria, R., Lavini, A. and Morelli, G. (2006) The Effect of Deficit Irrigation on Crop Yield and Vegetative Development of Olea europaea L. (cvs. Frantoio and Leccino). European Journal of Agronomy, 25, 356-364. http://dx.doi.org/10.1016/j.eja.2006.07.003

[10] Allen, R., Pereira, L.S., Raes, D. and Smith, M. (1998) Crop Evapotranspiration, Guidelines for Computing Crop Water Requirements. FAO Irrigation and Drainage Paper No. 56, FAO, Rome.

[11] Correa-Tedesco, G., Cecilia Rousseaux, M. and Searles, P.S. (2010) Plant Growth and Yield Responses in Olive (Olea europaea) to Different Irrigation Levels in an Arid Region of Argentina. Agricultural Water Management, 97, 18291837. http://dx.doi.org/10.1016/j.agwat.2010.06.020

[12] Pérez-López, D., Ribas, F., Moriana, A., Olmedilla, N. and de Juan, A. (2007) The Effect of Irrigation Schedules on the Water Relations and Growth of a Young Olive (O. europaea L.) Orchard. Agricultural Water Management, 89, 297-304. http://dx.doi.org/10.1016/j.agwat.2007.01.015

[13] Gómez-del-Campo, M. (2013) Summer Deficit Irrigation in a Hedgerow Olive Orchard cv. Arbequina: Relationship between Soil and Tree Water Status, and Growth and Yield Components. Spanish Journal of Agricultural Research, 11, 547. http://dx.doi.org/10.5424/sjar/2013112-3360

[14] Grattan, S.R., Berenguer, M.J., Connell, J.H., Polito, V.S. and Vossen, P.M. (2006) Olive Oil Production as Influenced by Different Quantities of Applied Water. Agricultural Water Management, 85, 133-140. http://dx.doi.org/10.1016/j.agwat.2006.04.001 